\title{
THE BALD EAGLE OF NORTH AMERICA
}

$\mathrm{A}$ I'ACHED to the bald eagle is a degree of popular interest far beyond that normally associated. with other birds of prey. Early in the history of the United States the bald eagle, of all the varied forms of wildlife in North America, was selected as the national emblem. By act of Congress, on June 20, 1782 , a design for the national coat-of-arms displaying the bald eagle was adopted.

In a paper published by the Fish and Wildlife Service of the United States Department of the Interior*, Ralph H. Imler and E. R. Kalmbach have reviewed the economic status of the bird. Information has been assembled from reliable sources, from the examination of a series of stomachs and crops of bald eagles, and food romains at nests, to permit a current appraisal of the economics of the bird both within the borders of the United States and in the Territory of Alaska. Study of the economics of the bald eagle was prompted largely by the need for information to appraise the merits of bounty and other legislation affecting the eagle in the Territory of Alaska, where it long has been the subject of controversy. Although the bald eagle was noticeably reduced in south-eastern Alaska during the years of bounty payments after 1917, there are indications that the bird is now regaining its numbers and may again assume its former abundance in favoured areas.

* Fish and Wildlife Service of the United States Department of the Interior. Circular 30: The Bald Eagle and its Economic Status By Ralph H. Imler and E. R. Kalmbach. Pp. ii $+295-330$.
As a basis for laboratory food studies, 435 stomachs of Alaskan bald eagles were collected and examined. In addition, data are available from thirty-one stomachs collected in the United States, and six stomachs collected in Canada. Nearly two-thirds of the food of Alaskan eagles was composed of fish, and of this about one-sixth ( 16.9 per cent) was salmon. Imler and Kalmbach believe that most of the salmon was carrion when found by the birds. An appreciable, but uncertain, portion of the other fish consumed was known to be dead when located by the eagles. Less than one-fifth (18.8 per cent) of the Alaskan eagles' food was derived from birds, the remainder being various marine species plentiful in the north Pacific.

Stomach examination has substantiated to a limited extent the reported predation of the bald eagle on deer. There is no evidence that the bald eagle exerts an appreciable effect on the population of small mammals unless it should be during winter when numbers of these birds may congregate in areas where jackrabbits are abundant.

Only in Alaska is the bald eagle abundant enough to constitute a significant hazard to domestic livestock, and even there its most important relation is with the semi-domesticated blue fox. During recent years, this problem has been materially alleviated, the more progressive raisers confining their animals under screens. Within the United States, the bald eagle has occasionally preyed on domestic poultry, but here again the small number it takes makes the total effect insignificant.

\section{ORIGIN OF THE CHARACTERISTIC ENERGY LOSSES OF ELECTRONS IN SOLIDS}

\author{
By DR. E. J. STERNGLASS \\ Westinghouse Research Laboratories, Pittsburgh 35, Pennsylvania
}

\begin{abstract}
$\mathrm{T}$ HE characteristic energy losses of electrons passing through thin foils ${ }^{1}$ have been interpreted in terms of collective oscillations by $\mathrm{Bohm}$ and Pines $^{2}$ and in terms of high-lying 'quasi-stationary' excited states by Hayasi ${ }^{3}$. It is the purpose of the present article to outline an alternative explanation in terms of individual atomic ionization and excitation processes according to the Bohr-Bethe theory for the stopping of charged particles.

On this interpretation, the principal energy loss occurring for all substances between approximately 12 and $22 \mathrm{eV}$. represents the ionization of the bound shell next to the valence-level, for which the binding energies range from about 10 to $20 \mathrm{eV}$. throughout the atomic table. The weaker loss lines below $\sim 12 \mathrm{eV}$. are considered to represent excitations and ionizations of the valence electrons. As indicated schematically in Fig. 1, the ionization processes give rise to a characteristically asymmetrical energy loss peak of the same form as the known energy distribution curves of the secondary electrons ${ }^{4}$. The form of the secondary electron energy distribution
\end{abstract}

curve and the location of the peak at about $2 \mathrm{eV}$. above the zero energy vacuum reference-level is predicted by the theory of ionization ${ }^{5}$ and has been observed to be essentially the same for gases ${ }^{6}$, metals ${ }^{4}$ and insulators ${ }^{4}$. Since the half-width of these curves is only about $2-4 \mathrm{eV}$., the narrow peak is equivalent to a rather well-defined final state required to explain

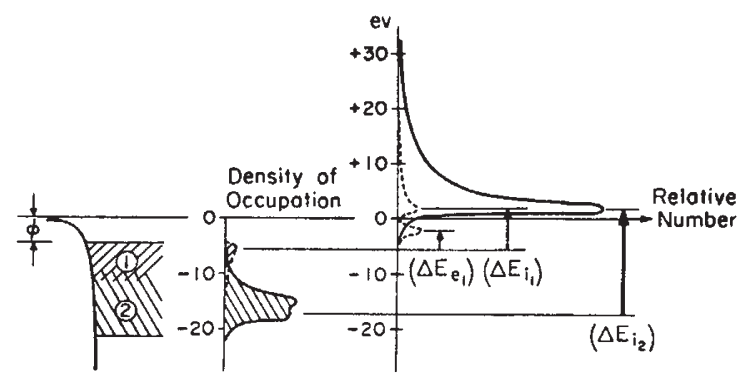

Fig. 1. Schematic diagram illustrating the fundamental energyloss processes 